\title{
Preparation and Sealing Processing of Sodium Alginate Based Blending Film
}

\author{
Liqiang Wang, ${ }^{1,2}$ Osvaldo Campanella, ${ }^{3}$ Bhavesh Patel, ${ }^{3}$ and Lixin Lu' \\ ${ }^{1}$ Department of Packaging Engineering, Jiangnan University, Wuxi, Jiangsu 214122, China \\ ${ }^{2}$ Jiangsu Key Laboratory of Advanced Food Manufacturing Equipment and Technology, Jiangnan University, \\ Wuxi, Jiangsu 214122, China \\ ${ }^{3}$ Agricultural and Biological Engineering Department, Purdue University, West Lafayette, IN 47907, USA
}

Correspondence should be addressed to Liqiang Wang; wlqcom@163.com

Received 14 September 2014; Revised 20 January 2015; Accepted 27 January 2015

Academic Editor: Dong Sun Lee

Copyright (C) 2015 Liqiang Wang et al. This is an open access article distributed under the Creative Commons Attribution License, which permits unrestricted use, distribution, and reproduction in any medium, provided the original work is properly cited.

Edible packaging has been successfully used for packaging of low moisture foods such as wrappers. One of the hurdles in the use of edible packaging for moisture rich foods is its ability to successfully seal the package, which is critical due to the lower strength and elastic characteristics of edible films compared to plastic based films. Three important sealing parameters, namely, adhesive concentration, pressure, and temperature during sealing, were investigated to assess sealing performance of the edible film. The edible film was prepared from blend of three polymers (sodium alginate, sodium carboxymethyl cellulose, and gelatin) based on previous research work. The seal was evaluated for seal strength and a quadric regression model to predict seal strength as a function of adhesive concentration, pressure, and temperature during sealing was established. The model was statistically significant $(P<0.05)$ and an optimum combination of sealing parameters was obtained to be $24.4 \%$ adhesive concentration, $0.28 \mathrm{MPa}$ pressure, and $153^{\circ} \mathrm{C}$ temperature. A sealing time of $1 \mathrm{~s}$ was used for all samples. All three factors were significant taken individually and interactions of the three factors were also significant $(P<0.05$ or 0.10$)$ except for the interaction between adhesive concentration and sealing temperature.

\section{Introduction}

The increase in consumer demand for environmental-friendly food packaging and longer shelf life has encouraged further research into use of natural biopolymer materials such as packaging materials especially edible films. The biopolymers used as raw materials of edible films should be capable of forming a continuous matrix and normally are obtained from renewable and abundant sources [1]. Edible films are generally thin layers, which can be consumed, coated on a food or placed as barrier between the food and the surrounding environment to preserve its natural organoleptic properties and to prolong its shelf life $[2,3]$. Most of the common edible film-forming materials can be classified as either polysaccharides based (e.g., agar [4], alginate [5], carrageenan, cellulose and their derivatives, chitin, chitosan, pectin, and starch) or proteins based (e.g., collagen, gelatin, keratin, whey, casein, zein, wheat gluten, and soy protein $[2,4-6])$. Additional functional additives used in edible film making are particularly plasticizers, cross-linking agents, antioxidants, and antimicrobials agents to improve mechanical, qualitative, and organoleptic properties of the films. In the last 30 years, edible films made from a variety of natural compounds have been reported. In recent years, studies and applications of edible films on food packaging continue to increase due to the role of edible films in maintaining food quality effectively $[2,3]$. However, most of these studies were focused on the mechanical properties (tensile strength and percentage elongation at break), barrier properties (against water vapor, $\mathrm{CO}_{2}$, oxygen, aromatic substances, or oils), antibacterial properties, light transmission, thermal properties, and their formation $[2,7]$. Sealing property of edible films is a very 
important assessment index for packaging film materials which has not been investigated by many researchers. In the packaging industry, high temperature sealing is widely used to join polymeric films [7]. However, studies on seal ability and seal properties of edible film were scarce; most of the literature only reported the measurement values of sealing strength of the edible films. Kim and Ustunol [7] discussed the effect of sealing temperature, pressure, and time on seal strength of whey protein isolate and lipid emulsions based edible films. In addition, there is no information available on sealing process variables for edible films, especially in the sealing properties of using an adhesive in sodium alginate (SA)/sodium carboxymethyl cellulose (SCMC)/gelatin based blending film. One of the main problems for successful application of edible film in practical packaging application is the poor mechanical properties and sealing performance. Most of the damage to edible packaging film is observed near sealing area; thus the sealing performance of the edible films has a direct impact on the overall packaging quality. The goal of this research was to develop a sealing protocol for edible films prepared using a blend of SA/SCMC/gelatin with good mechanical properties in order to optimize the sealing parameters, namely, sealing temperature, sealing pressure, and adhesive concentration.

\section{Materials and Methods}

2.1. Materials. Sodium alginate was purchased from TIC Gums, Inc. (MD, USA), sodium carboxymethyl cellulose (type 7MF) was obtained from Hercules Incorporated (Delaware, USA), and gelatin (G2500) was obtained from Sigma-Aldrich (USA). Glycerol was used as plasticizer.

\subsection{Experimental Methods}

2.2.1. Preparation of Film Sample. Sodium alginate, SCMC, and gelatin powders were weighed and mixed to get total weight of $4.5 \mathrm{~g}$ (3.0:1.0:0.5 ratio) and dissolved in $100 \mathrm{~mL}$ distilled water. After dispersing the dry ingredients uniformly in water, $2.25 \mathrm{~g}$ glycerol was added as plasticizer. The solution was heated at $50^{\circ} \mathrm{C}$ in hot water bath (Cole-Parmer EW14575-12, location) heated for $2 \mathrm{~h}$ and mixed using a magnetic stirrer for $2 \mathrm{~h}$ to form a homogeneous film-forming solution [8]. Finally the solution was heated in microwave at power of $300 \mathrm{~W}$ for 3 minutes. Solutions were finally cooled to $25^{\circ} \mathrm{C}$ and mixed gently for $60 \mathrm{~min}$ to facilitate removal of air bubbles [9]. Afterwards, $35 \mathrm{~mL}$ of the film-forming solution was poured onto $16 \times 18 \mathrm{~cm}$ polyacrylic film casting plates, followed by drying in a vacuum drying oven at $65^{\circ} \mathrm{C}$ for $12 \mathrm{~h}$. The resulting films were peeled off from the polyacrylic plates and conditioned at $23^{\circ} \mathrm{C}$ and $50 \pm 2 \% \mathrm{RH}$ prior to further testing. Film samples were tested in triplicate [10].

2.2.2. Film Thickness. Film thickness was determined using an IP65 Mitutoyo digital micrometer (Mitutoyo Ltd., Japan). Measurements were taken at 5 locations on the film and mean thickness was reported. The mean thickness of the SA/SCMC/gelatin-glycerol films was $40 \pm 3 \mu \mathrm{m}$ [10].
2.2.3. Film Sealing and Seal Strength Determination. To facilitate the sealing of film, gelatin solution was used as an adhesive. The adhesive solution (concentration was 20$28 \%$ ) was prepared by mixing the right weight of gelatin in $10 \mathrm{~mL}$ of deionized water for $1 \mathrm{~h}$ in $60^{\circ} \mathrm{C}$ water bath (EW14575-12, Cole-Palmer). Film samples for sealing strength test were prepared according to the ASTM standard method D882-02 (ASTM, 2002). The film samples were cut into strips of dimensions $15 \times 100 \mathrm{~mm}$, and an area of $15 \times 25 \mathrm{~mm}$ at the edge of the film strip was coated evenly on one side with $0.2 \mathrm{~mL}$ of the adhesive solution. Two film strips were placed on top of one another, and the area of coated gelatin adhesive solution was put together and heat-sealed at different temperature and pressure for $1 \mathrm{~s}$ dwell time, using a thermal heat-sealer Model SL-2 (LAKOTOOL \& MF Corp., USA), and sealing width of $20 \mathrm{~mm}$. The film samples were dried at room temperature $\left(23^{\circ} \mathrm{C}\right)$ for $16 \mathrm{~h}$. The sealed film samples were stored at $23^{\circ} \mathrm{C}$ and $50 \% \mathrm{RH}$ following drying for at least $48 \mathrm{hrs}$ until tested. Seal strength of the heatsealed films was determined according to Standard ASTM F-88 (ASTM 2009), using an Intelligent Universal Testing Machine Model XLW-500N (Labthink, Jinan, China), at $23^{\circ} \mathrm{C}$ and $50 \%$ RH. Each end of the sealed film sample was clamped perpendicularly to the direction of the pull. The film sample length, that is, distance between the clamps, was $50 \mathrm{~mm}$ and a crosshead speed of $300 \mathrm{~mm} / \mathrm{min}$ was used to test the seal strength. The sealed film sample was stretched with increasing load until it was completely stripped from the sealing part. Seal strength was recorded as the maximum force per unit width of film $(\mathrm{N} / \mathrm{m})$ required to strip the seal [7].

2.2.4. Thermophysical Property of Film. The film sample was characterized thermophysically using a Q2000 Differential Scanning Calorimeter (DSC) (TA Instruments, Inc., DE, USA). The film sample ( $6.0 \mathrm{mg})$ was sealed in hermetic aluminum pan and heated from -40 to $200^{\circ} \mathrm{C}$ at $10^{\circ} \mathrm{C} / \mathrm{min}$ heating rate. The resulting thermogram was analyzed using the Universal Analysis 2000 (version 4.5a) software (TA Instruments, Inc., DE, USA); melting endotherm peak temperature was recorded as film melting temperature (the adhesive was not used for thermal tests).

2.2.5. Experimental Design. A three-factor, five-level quadric regression rotation combination design was chosen to study the effects of SA/SCMC/gelatin blend films on the sealing properties. The variables range was established using the results from a single factor preliminary experiment [11]. The range for adhesive concentration was $20-28 \%$, the sealing temperature $140-160^{\circ} \mathrm{C}$, and the sealing pressure $0.2-$ $0.4 \mathrm{MPa}$. The experiments within these ranges of independent variables appeared to work well with no seal deformation. The five levels of each variable were coded as $-1.682,-1,0,+1$, and +1.682 . The experimental design (Table 1) consisted of 20 design points and included 6 replications of the central point. The order of the experiments was fully randomized [10]. The results were analyzed using Design Expert 8.0 software (StatEase, Inc., MN, USA). 
TABLE 1: Film sealing experiment design with coded and real values for adhesive concentration, sealing temperature, and sealing pressure along with response variable of seal strength.

\begin{tabular}{|c|c|c|c|c|c|c|c|}
\hline \multirow{3}{*}{$\begin{array}{l}\text { Trial } \\
\text { number }\end{array}$} & \multicolumn{6}{|c|}{ Independent variables } & \multirow{3}{*}{$\begin{array}{c}\text { Response variable } \\
\text { Seal strength }(\mathrm{N} / 15 \mathrm{~mm})\end{array}$} \\
\hline & \multicolumn{3}{|c|}{ Coded values } & \multicolumn{3}{|c|}{ Real values } & \\
\hline & $X_{1}$ & $X_{2}$ & $X_{3}$ & Adhesive concentration (\%) & Sealing temperature $\left({ }^{\circ} \mathrm{C}\right)$ & Sealing pressure $(\mathrm{MPa})$ & \\
\hline 1 & 1 & 1 & 1 & 26 & 155 & 0.35 & 21.33 \\
\hline 2 & 1 & 1 & -1 & 26 & 155 & 0.25 & 24.66 \\
\hline 3 & 1 & -1 & 1 & 26 & 145 & 0.35 & 23.13 \\
\hline 4 & 1 & -1 & -1 & 26 & 145 & 0.25 & 19.23 \\
\hline 5 & -1 & 1 & 1 & 22 & 155 & 0.35 & 20.13 \\
\hline 6 & -1 & 1 & -1 & 22 & 155 & 0.25 & 24.09 \\
\hline 7 & -1 & -1 & 1 & 22 & 145 & 0.35 & 18.16 \\
\hline 8 & -1 & -1 & -1 & 22 & 145 & 0.25 & 20.17 \\
\hline 9 & 1.682 & 0 & 0 & 27.364 & 150 & 0.3 & 19.81 \\
\hline 10 & 1.682 & 0 & 0 & 20.636 & 150 & 0.3 & 16.50 \\
\hline 11 & 0 & 1.682 & 0 & 24 & 158.41 & 0.3 & 23.04 \\
\hline 12 & 0 & 1.682 & 0 & 24 & 141.59 & 0.3 & 21.67 \\
\hline 13 & 0 & 0 & 1.682 & 24 & 150 & 0.384 & 20.63 \\
\hline 14 & 0 & 0 & 1.682 & 24 & 150 & 0.216 & 23.36 \\
\hline 15 & 0 & 0 & 0 & 24 & 150 & 0.3 & 25.35 \\
\hline 16 & 0 & 0 & 0 & 24 & 150 & 0.3 & 24.93 \\
\hline 17 & 0 & 0 & 0 & 24 & 150 & 0.3 & 25.56 \\
\hline 18 & 0 & 0 & 0 & 24 & 150 & 0.3 & 24.20 \\
\hline 19 & 0 & 0 & 0 & 24 & 150 & 0.3 & 24.82 \\
\hline 20 & 0 & 0 & 0 & 24 & 150 & 0.3 & 24.20 \\
\hline
\end{tabular}

TABLE 2: The results of quadratic model fitting tabulated as analysis of variance for the film sealing experiment.

\begin{tabular}{|c|c|c|c|c|c|c|}
\hline Source & Sum of squares & $\mathrm{df}$ & Mean square & $F$ value & \multicolumn{2}{|c|}{$P$ value $($ Prob $>F)$} \\
\hline Model & 123.67 & 9 & 13.74 & 42.87 & $<0.0001$ & Significant \\
\hline$A$-adhesive & 14.91 & 1 & 14.91 & 46.5 & $<0.0001$ & Significant \\
\hline$B$-sealing temperature & 3.3 & 1 & 3.3 & 10.28 & 0.0107 & Significant \\
\hline$C$-sealing pressure & 12.43 & 1 & 12.43 & 38.77 & 0.0002 & Significant \\
\hline$A B$ & 0.42 & 1 & 0.42 & 1.31 & 0.2827 & Not significant \\
\hline$A C$ & 10.87 & 1 & 10.87 & 33.91 & 0.0003 & Significant \\
\hline$B C$ & 16.74 & 1 & 16.74 & 52.24 & $<0.0001$ & Significant \\
\hline$A^{\wedge} 2$ & 75.17 & 1 & 75.17 & 234.55 & $<0.0001$ & Significant \\
\hline$B^{\wedge} 2$ & 9.71 & 1 & 9.71 & 30.31 & 0.0004 & Significant \\
\hline$C^{\wedge} 2$ & 12.91 & 1 & 12.91 & 40.28 & 0.0001 & Significant \\
\hline Residual & 2.88 & 9 & 0.32 & & & \\
\hline Lack of fit & 1.28 & 4 & 0.32 & 0.99 & 0.4877 & Not significant \\
\hline Pure error & 1.61 & 5 & 0.32 & & & \\
\hline
\end{tabular}

\section{Results and Analysis}

3.1. Analysis of Variance. The structure of quadric regression rotation matrix and the results can be seen from Table 1 . The sealing variables conditions of blend films were conducted and optimized by three-factor, five-level quadric regression rotation combinational design. The test data were analyzed using the multiple regression model consisting of three factors. Preliminary analysis of the ANOVA results computed using Design Expert software (State Ease, MN, USA) using the data (Table 1) showed that even though the model was statistically significant, it had significant lack of fit. Using the diagnostic tool (Cook's Distance) data point from trial 5 (Table 1) was removed from ANOVA analysis and the new results presented in Table 2 have nonsignificant lack of fit. In the terms of coded values, the response surfaces could be generated from the following equation:

$$
\begin{aligned}
Y= & 24.836+1.155 X_{1}+0.543 X_{2}-1.054 X_{3} \\
& -2.318 X_{1}^{2}+0.269 X_{1} X_{2}-0.833 X_{2}{ }^{2} \\
& +1.369 X_{1} X_{3}-1.699 X_{2} X_{3}-0.961 X_{3}{ }^{2}
\end{aligned}
$$


where $Y$ represents the seal strength response and $X_{1}, X_{2}$, and $X_{3}$ represent the coded values for the three factors, namely, adhesive concentration, sealing temperature, and sealing pressure, respectively. Each of these three factors, in the order mentioned, yielded linear coefficients +1.155 , +0.543 , and -1.054 ; interaction coefficients $+0.269,+1.369$, and -1.699; and quadratic coefficients $-2.318,-0.833$, and -0.961 , respectively, with a $Y$ intercept of 24.836 . The results of analysis of variance from the regression model are listed in Table 2. It shows that $F_{\mathrm{Reg}}=42.87>F_{0.01}(9,10)=4.94$ and the regression equation (1) is highly significant; $F_{\mathrm{LF}}=$ $0.995<F_{0.05}(5,5)=5.05$ and the lack of fit $(\mathrm{LF})$ of the regression equation is not significant. Therefore, (1) can be used for the prediction of the seal strength within the range of the experimental design. Further, Table 2 also shows that regression coefficients of quadratic term are all significant, which means that each of the single factors $(X)$ exhibits significant quadric relationship with the seal strength. The other interactive regression coefficients of the equation have different levels of significance except for $X_{1} X_{2}\left(F_{X_{1} X_{2}}=\right.$ $\left.1.31<F_{0.1}=3.29\right)$, which is not significant. These results show that there are interaction effects among the three factors, which coincides with practical situations.

Final equation in terms of actual factors follows:

$$
\begin{aligned}
\text { Seal Strength }= & -1228.02 \\
& +20.262 * \text { Adhesive Concentration } \\
& +11.502 * \text { Sealing Temperature } \\
& +900.15 * \text { Sealing Pressure } \\
& +0.03 * \text { Adhesive Concentration } \\
& * \text { Sealing Temperature } \\
& +13.69 * \text { Adhesive Concentration } \\
& * \text { Sealing Pressure } \\
& -6.79 * \text { Sealing Temperature } \\
& * \text { Sealing Pressure } \\
& -0.58 *(\text { Adhesive Concentration })^{2} \\
& -0.03 *(\text { Sealing Temperature })^{2} \\
& -384.28 *(\text { Sealing Pressure })^{2} .
\end{aligned}
$$

3.2. Factors Significance Analysis. The data were analyzed using Design Expert 8.0 (Stat-Ease, MN, US), and the regression sum of squares of the three factors was $S S_{1}=14.9$, $S S_{2}=3.3$, and $S S_{3}=12.4$. The results showed the order of significance of each factor is adhesive concentration $\left(X_{1}\right)>$ sealing pressure $\left(X_{3}\right)>$ sealing temperature $\left(X_{2}\right)$.

3.3. Single Factor Effect Analysis. When the other two factors were fixed at " 0 " coded level the regression equation gives the

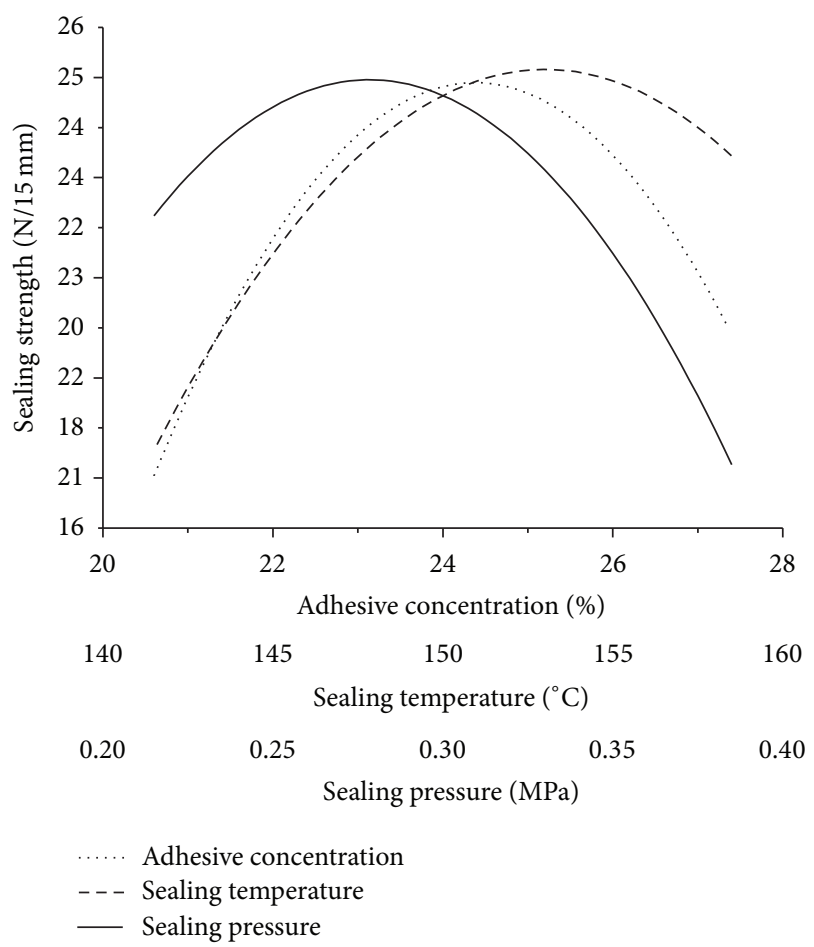

FIGURE 1: Line graph showing relationship between sealing strength and all three factors (adhesive concentration, sealing temperature, and sealing pressure).

relationship between the third factor and the seal strength. According to Figure 1, a relationship between each of the three single factors and the seal strength (Figure 1) was obtained. As seen in Figure 1, with the increase in sealing temperature, the seal strength increased up to $155^{\circ} \mathrm{C}$ sealing temperature and above $153^{\circ} \mathrm{C}$ it started to decline. This behavior was expected because the film samples show an endothermic transition in DSC thermogram, which reflects film melting at higher temperatures. The characteristic film melting temperature was $147.3^{\circ} \mathrm{C}$. The inset in Figure 2 clearly shows the relationship between melting endotherm and seal strength. The seal strength increases as sealing temperature approaches melting peak temperature and keeps increasing beyond melting temperature up to $153^{\circ} \mathrm{C}$. However, as temperature increased beyond $153^{\circ} \mathrm{C}$, the seal strength starts to decrease. This might be explained by an increased tendency of the material to flow at temperatures beyond its melting point, which in combination with sealing pressure might lead to reduction in thickness of film in and around the sealed region which might weaken the resulting seal strength. The ascending gradient in seal strength was larger than the descending gradient; when the sealing temperature increased from $141^{\circ} \mathrm{C}$ to $153^{\circ} \mathrm{C}$, the seal strength would increase significantly. When the seal temperature was at about $153^{\circ} \mathrm{C}$, the seal strength reached the maximum. Therefore, in the actual process, the control of the sealing temperature in the optimum range could not only improve the seal strength, but also save energy.

With the gradual increasing of adhesive concentration and sealing pressure, the seal strength also presented the 


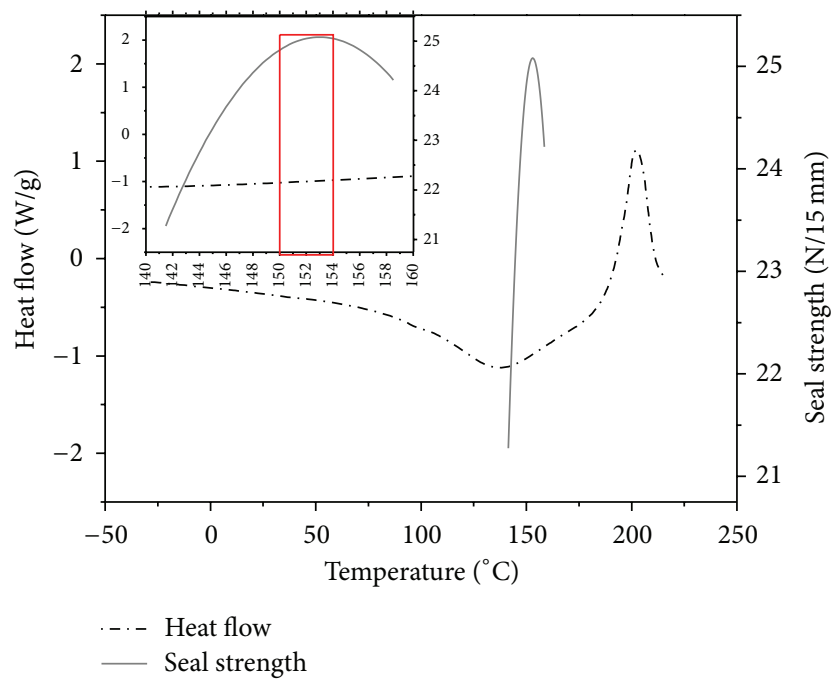

FIGURE 2: Film sealing strength and sealing temperature with the DSC thermogram for film sample.

same trend as the seal temperature. The curve of sealing pressure showed a slightly lower ascending gradient than the descending gradient. As the sealing pressure value reached about $0.28 \mathrm{MPa}$, the response value of seal strength reached the maximum. The curve of adhesive concentration had similar ascending and descending rates. When the adhesive concentration reached a value of about $24.4 \%$, the seal strength was the highest. These results suggest that, in sealing process of this blend film, an optimum point existed when we analyze the effect of each factor individually for seal strength. These variable values either too high or too low would decrease the seal strength sharply as the sealing process of the edible blend films appears to have strict requirements on sealing temperature, sealing pressure, and adhesive concentration. Therefore, the effective control of each factor is required to obtain the optimum sealing process, which ensures maximum seal strength.

3.4. Interaction Analysis between Two Factors. In the regression equation (1), one factor at " 0 " coded level was fixed in order to analyze the interaction effect between the other two factors. The data analysis results (Table 2) show that the interaction between adhesive concentration and the sealing pressure $\left(X_{1} X_{3}\right)$ was significant and the interaction between sealing temperature and sealing pressure $\left(X_{2} X_{3}\right)$ was also very significant.

3.4.1. Adhesive Concentration and Sealing Pressure $\left(X_{1} X_{3}\right)$. The interaction of adhesive concentration and sealing pressure on the seal strength can be seen in Figures 3(a) and 3(b). When the sealing temperature was fixed at $150^{\circ} \mathrm{C}$, increases of sealing adhesive concentration and sealing pressure resulted in an obvious increase and then decrease of the seal strength. To obtain a better seal strength, the optimal scope of adhesive concentration should be at the coded value of $0 \sim 0.2$ (real value 24\% 24.4\%); optimal sealing pressure should be at the coded value between -0.2 and -0.45 (real value 0.278 $0.29 \mathrm{MPa}$ ). The effect of adhesive concentration on seal strength was more sensitive when compared to the sealing pressure. In addition, results suggest that the adhesive concentration was the most important individual factor having a significant effect on the seal strength, which is consistent with the analysis mentioned above.

3.4.2. Sealing Temperature and Sealing Pressure $\left(X_{2} X_{3}\right)$. With the adhesive concentration $\left(X_{1}\right)$ fixed at $24 \%$ Figure $4(\mathrm{a})$ shows that initial increases were followed by a decrease in film strength as sealing temperature and sealing pressure values increased. The surface plot (Figure 4) shows that as sealing temperature and sealing pressure values increased from low to high the seal strength represented by the surface increased to a peak and gradually fell indicating the interaction between these two factors. Thus, in order to have a better seal strength combinations of low sealing pressure/low sealing temperature and high sealing pressure/high sealing temperature should not be used. The contour plot (Figure 4(b)) clearly shows that within the range of variables examined the maximum seal strength can be achieved at sealing temperature of $157.5^{\circ} \mathrm{C}$ at a sealing pressure of $0.225 \mathrm{MPa}$. In other words, in the sealing process of the SA/SCMC/gelatin blend film, when other conditions remained unchanged, to enhance the seal strength efficiently, the combination of relatively low sealing pressures and relatively high sealing temperatures could be used for the sealing process in order to meet package requirements. This observation is also intuitively true because as temperature increases the tensile strength of the film will decrease; hence a lower sealing pressure could be used to avoid film breakage.

3.5. Optimization and Results Verification of Sealing Variables. When the values of sealing variables were estimated to maximize the seal strength $(Y)$ within the limits of the independent experimental variables used as an evaluation criterion a mathematical model can be established as follows:

$$
\begin{aligned}
& \text { the objective function: } Y\left(X_{1}, X_{2}, X_{3}\right) \rightarrow \max \text {, } \\
& \text { constraint conditions: }-2 \leq X_{1} \leq 2,-2 \leq X_{2} \leq 2 \text {, } \\
& \text { and }-2 \leq X_{3} \leq 2 \text {. }
\end{aligned}
$$

The Newton iterative programming method was used to calculate the radix in order to obtain the optimum technological parameter combination to provide the highest seal strength. The optimal values and calculated results are listed in Table 3. By means of the test verification, the theoretical calculated result was basically in accordance with the actual measurement result under this optimum condition and this proves that the mathematical model can be used as a guide for real life practical applications.

\section{Conclusions}

The results of the experimental analysis showed that the sequence (from strong to weak ) of the three factors having effect on seal strength of SA/SCMC/gelatin blend films was adhesive concentration, sealing pressure, and sealing 
Design Expert software

Factor coding: actual

Seal strength $(\mathrm{N} / 15 \mathrm{~mm})$

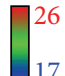

$X_{1}=A$ : adhesive concentration

$X_{2}=C$ : sealing pressure

Actual factor

$B$ : sealing temperature $=150.00$

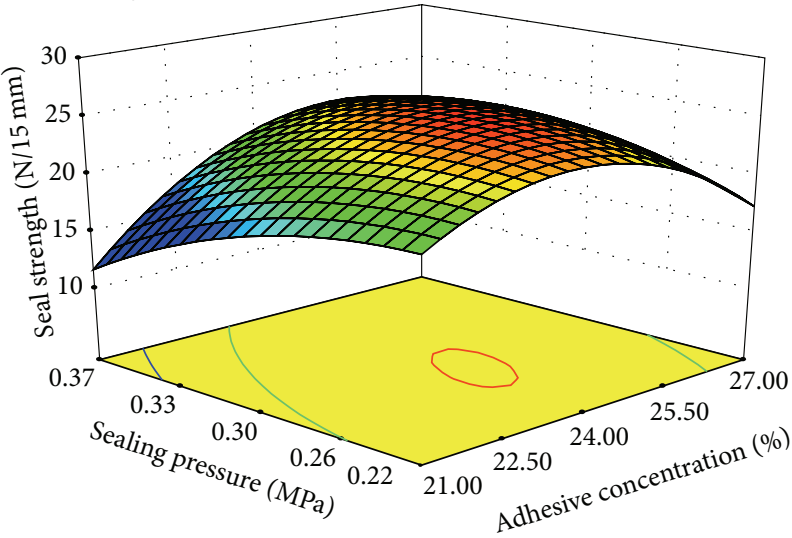

(a)
Design Expert software

Factor coding: actual

Seal strength $(\mathrm{N} / 15 \mathrm{~mm})$

$\prod_{17}^{26}$

$X_{1}=A$ : adhesive concentration

$X_{2}=C$ : sealing pressure

Actual factor

$B$ : sealing temperature $=150.00$

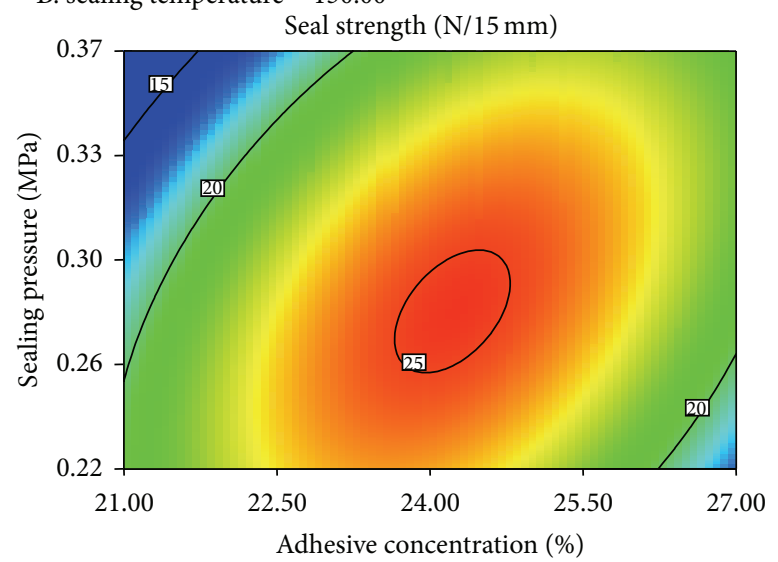

(b)

FIGURE 3: Sealing strength $(\mathrm{N} / 15 \mathrm{~mm})$ plot as a function of adhesive concentration and sealing pressure at $150^{\circ} \mathrm{C}$ sealing temperature. (a) Surface plot and (b) contour plot.

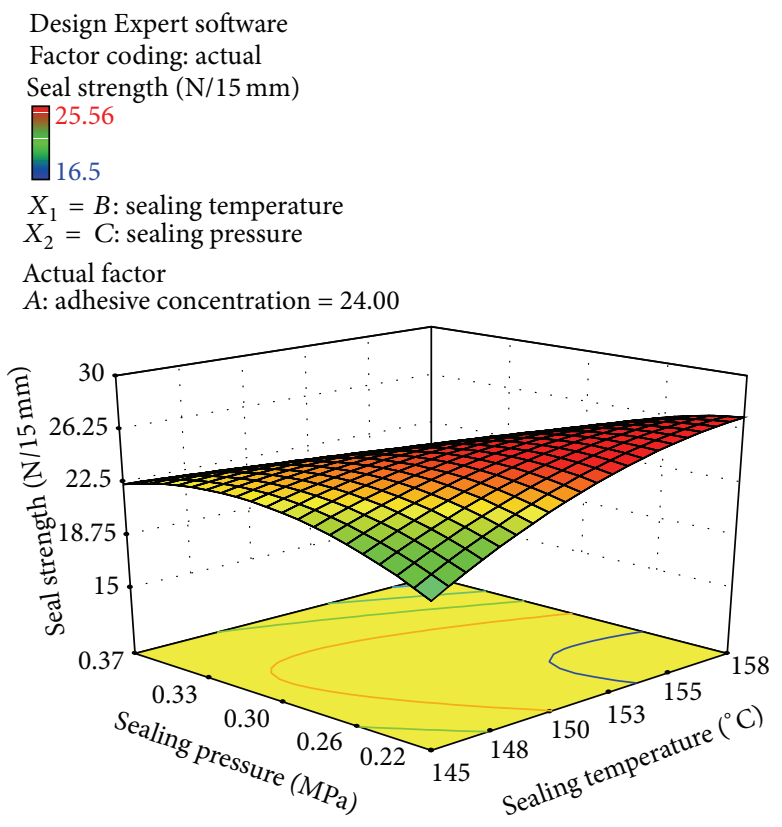

(a)

\author{
Design Expert software \\ Factor coding: actual \\ Seal strength (N/15 mm) \\ $\prod^{26}$ \\ 17 \\ $X_{1}=B$ : sealing temperature \\ $X_{2}=C$ : sealing pressure
}

Actual factor

$A:$ adhesive $=24.00$

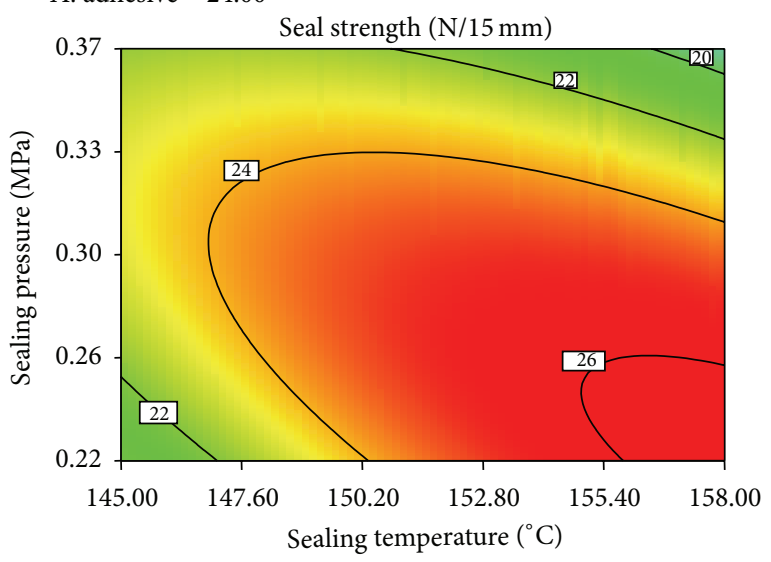

(b)

FIGURE 4: Sealing strength $(\mathrm{N} / 15 \mathrm{~mm})$ plot as a function of sealing temperature and sealing pressure at $24 \%$ adhesive concentration. (a) Surface plot and (b) contour plot. 
TABLE 3: Values for each of the three independent factors (adhesive concentration, sealing temperature, and sealing pressure) for optimized seal strength.

\begin{tabular}{lccc}
\hline & Optimum values & \multicolumn{2}{c}{ Sealing strength (N/15 mm) } \\
& Code value & Real & Theoretical value \\
\hline Adhesive concentration & 0.2 & $24.4 \%$ & 24.89 \\
Sealing pressure & 0.6 & $0.28 \mathrm{MPa}$ & 24.28 \\
Sealing temperature & -0.45 & $153^{\circ} \mathrm{C}$ & 24.46 \\
\hline
\end{tabular}

temperature. In the regression model presented previously, the effects of linear terms and the square terms on the seal strength were either significant $(P>0.05)$ or extremely significant $(P>0.01)$. With the increasing of level of each factor, seal strength showed first an ascending and then a descending trend. In the sealing process of SA/SCMC/gelatin blend films, each testing factor except for interaction of adhesive concentration and the sealing temperature $\left(X_{1} X_{2}\right)$ had either a significant or an extremely significant interaction with others. By optimizing the sealing conditions for seal strength $(24.9 \mathrm{~N} / 15 \mathrm{~mm})$, the optimum parameters of sealing process obtained were as follows: sealing adhesive concentration $24.4 \%$, sealing pressure $0.28 \mathrm{MPa}$, and sealing temperature $153^{\circ} \mathrm{C}$ under a sealing time of $1 \mathrm{~s}$.

\section{Conflict of Interests}

The authors declare that there is no conflict of interests regarding the publication of this paper.

\section{Acknowledgments}

This work was financially supported by the Fundamental Research Funds for the Central Universities (JUSRP21115), Science Foundation of Jiangnan University (no. 2007LQN18), the Research Program of Key Laboratory of Food Packaging Techniques and Safety of China National Packaging Corporation ([2008]114), PIRT Jiangnan, and the Startup Fund for Advanced Talents of Jiangnan University (no. 20700021050705).

\section{References}

[1] P. J. D. A. Sobral, J. S. Dos Santos, and F. T. García, "Effect of protein and plasticizer concentrations in film forming solutions on physical properties of edible films based on muscle proteins of a Thai Tilapia," Journal of Food Engineering, vol. 70, no. 1, pp. 93-100, 2005.

[2] P. Mokrejs, F. Langmaier, D. Janacova, M. Mladek, K. Kolomaznik, and V. Vasek, "Thermal study and solubility tests of films based on amaranth flour starch-protein hydrolysate," Journal of Thermal Analysis and Calorimetry, vol. 98, no. 1, pp. 299-307, 2009.

[3] O. Skurtys, C. Acevedo, F. Pedreschi, J. Enronoe, F. Osorio, and J. Aguilera, Food Hydrocolloid Edible Films and Coatings, Nova Science Publishers, 2010.

[4] T. D. Phan, F. Debeaufort, D. Luu, and A. Voilley, "Functional properties of edible agar-based and starch-based films for food quality preservation," Journal of Agricultural and Food Chemistry, vol. 53, no. 4, pp. 973-981, 2005.
[5] M. S. Tapia, M. A. Rojas-Graü, F. J. Rodríguez, J. Ramírez, A. Carmona, and O. Martin-Belloso, "Alginate- and gellan-based edible films for probiotic coatings on fresh-cut fruits," Journal of Food Science, vol. 72, no. 4, pp. E190-E196, 2007.

[6] A. Leerahawong, M. Tanaka, E. Okazaki, and K. Osako, "Stability of the physical properties of plasticized edible films from squid (Todarodes pacificus) mantle muscle during storage," Journal of Food Science, vol. 77, no. 6, pp. E159-E165, 2012.

[7] S.-J. Kim and Z. Ustunol, "Thermal properties, heat sealability and seal attributes of whey protein isolate/lipid emulsion edible films," Journal of Food Science, vol. 66, no. 7, pp. 985-990, 2001.

[8] J. A. Torres, "Edible films and coatings from proteins," in Protein Functionality in Food Systems, N. S. Hettiarachchy and G. R. Ziegler, Eds., IFT Basic Symposium Series, pp. 467-508, Marcel Dekker, New York, NY, USA, 1994.

[9] D. Peressini, B. Bravin, R. Lapasin, C. Rizzotti, and A. Sensidoni, "Starch-methylcellulose based edible films: rheological properties of film-forming dispersions," Journal of Food Engineering, vol. 59, no. 1, pp. 25-32, 2003.

[10] N. Pitak and S. K. Rakshit, "Physical and antimicrobial properties of banana flour/chitosan biodegradable and self sealing films used for preserving Fresh-cut vegetables," LWT-Food Science and Technology, vol. 44, no. 10, pp. 2310-2315, 2011.

[11] Y. Zhifa, Design and Analysis of Test, Higher Education Press, Beijing, China, 2000. 


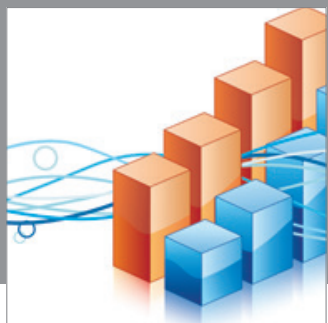

Advances in

Operations Research

mansans

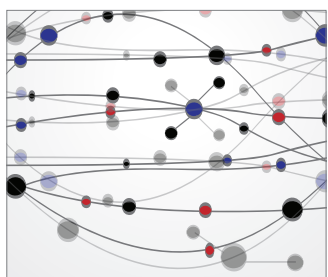

The Scientific World Journal
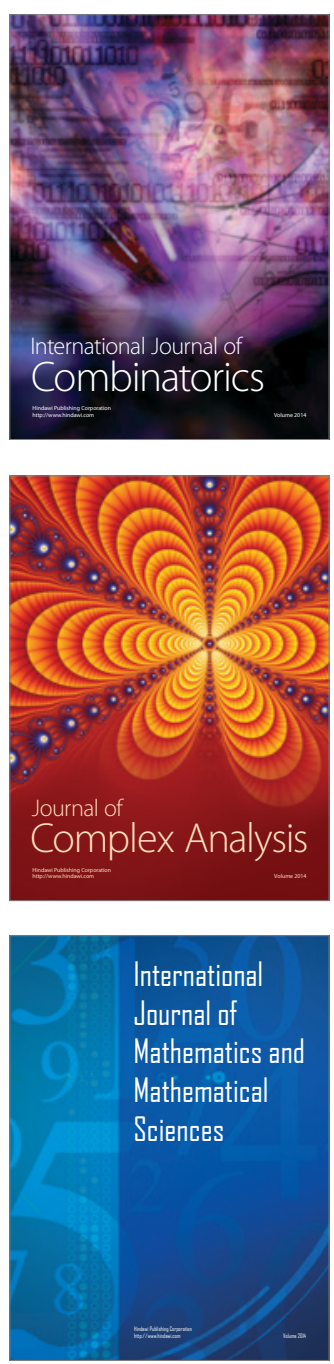
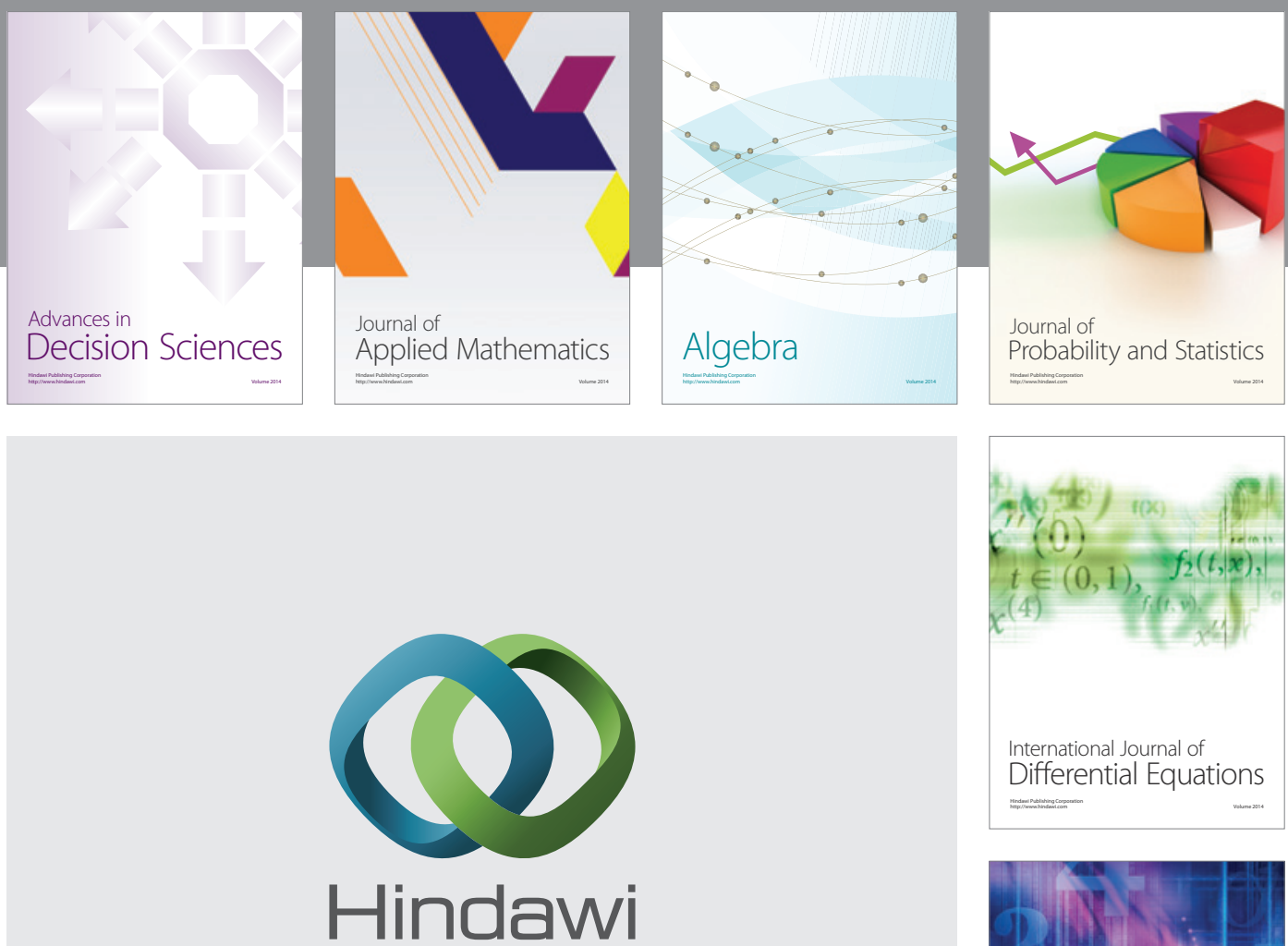

Submit your manuscripts at http://www.hindawi.com
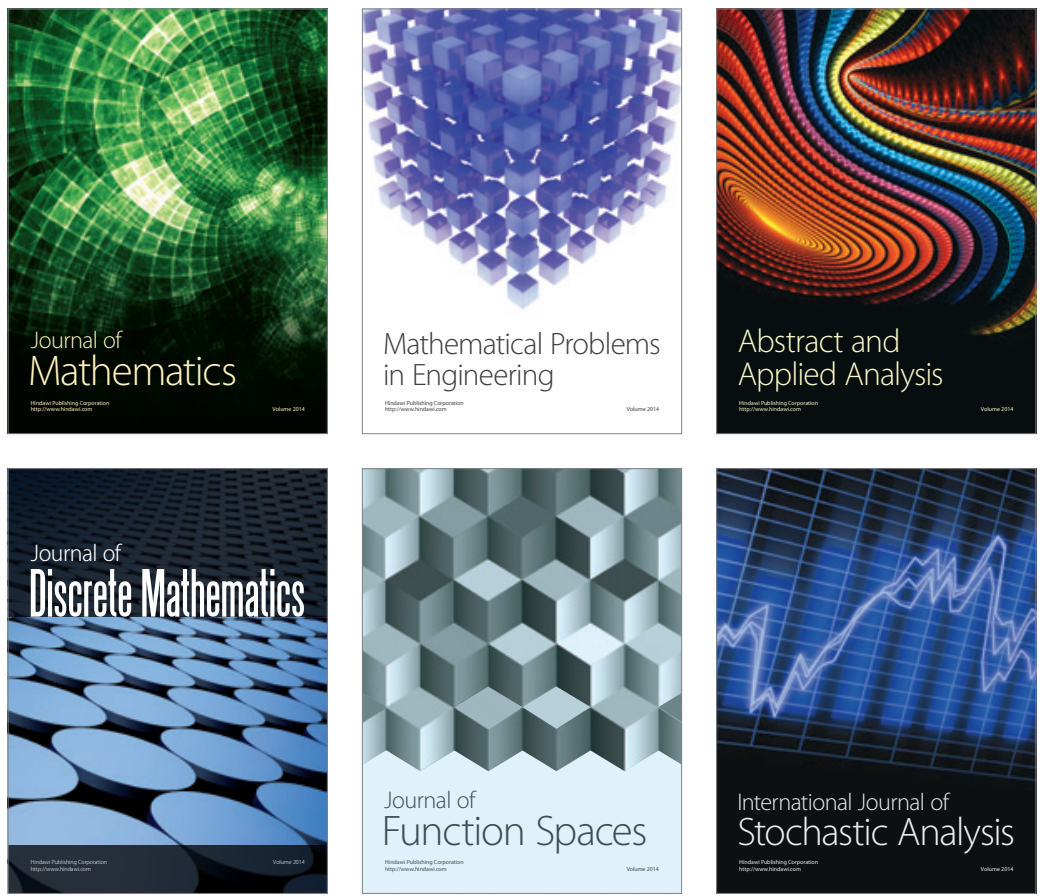

Journal of

Function Spaces

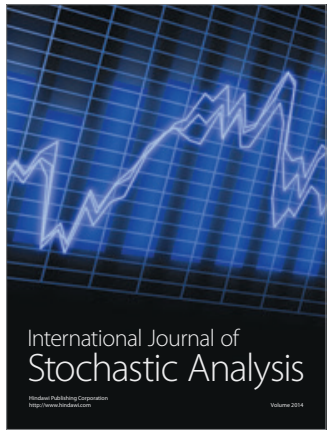

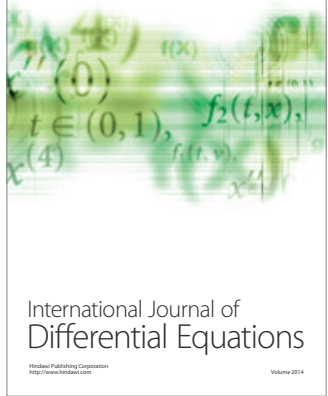
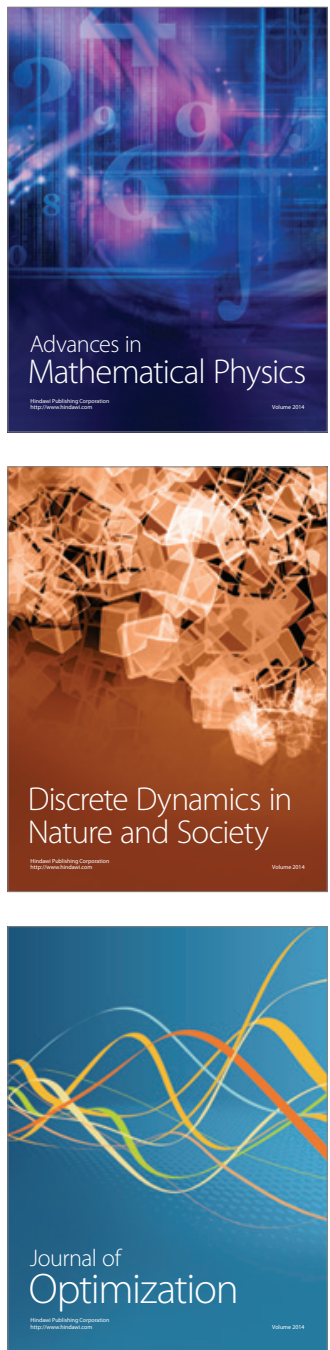